\title{
MAGISTRATURAS MUNICIPALES Y FUNCIONES RELIGIOSAS EN LA HISPANIA ROMANA(")
}

\author{
34(37): 352(46.Hispania)
}

por

\author{
Juan-Francisco Rodríguez Neila \\ Profesor de Historia Antigua \\ Universidad de Córdoba
}

\begin{abstract}
SUMARIO: I. INTRODUCCION.-II. EL FLAMINADO Y LAS CARRERAS ADMINISTRATIVAS LOCALES.-III. PECULIARIDADES DEL PONTIFICADO MUNICIPAL.-IV. LOS HONORES RELIGIOSOS DISPENSADOS A PERPETUIDAD.-V. CONCLUSIONES.
\end{abstract}

\section{INTRODUCCION}

La organización del culto sagrado entre los romanos presenta como característica fundamental su adscripción al poder político,

$\left(^{*}\right)$ Las abreviaturas utilizadas en el presente artículo se desarrollan del modo siguiente: A.E. Arq., Archivo Español de Arqueologia; A.Ep., L'Année Epigraphique; A.H.D.E., Anuario de Historia del Derecho Español; B.R.A.H., Boletín de la Real Academia de la Historia; Cabezón, ET, A. CABEzón, «Epigrafía tuccitana», A. E. Arq., XXXVII, 1964, págs. 106-155; CIL, Corpus Inscriptionum Latinarum (corresponden al volumen II-Hispania-los números que figuran tras las localidades donde se citan epigrafes); Eph.Ep., Ephemeris Epigraphica; Habis, 5, A. M. Canto, «Inscripciones inéditas andaluzas. I», Habis, V, 1974; H.A.E., Hispania Antiqua Epigraphica; IAGIL, M. Almagro, Las inscripciones ampuritanas, griegas, ibéricas y latinas, Barcelona, 1952; I. L. S., H. DesSAU, Inscriptiones Latinae Selectae; Lara, F. LARA, Epigrafía romana de Lérida, Lérida, 1973; M. A. N. L., Memorie dell'Accademia Nazionale dei Lincei, Roma; P. B.S.R., Papers of the British School at Rome, Londres; R. H.D., Revue d'Histoire du Droit, Groninga. 
en cuyas manos quedaron concentradas, tanto a nivel estatal como local, las potestades públicas y religiosas. La religión no fue, pues, algo configurado en torno a un grupo social diferente y privilegiado, sino simplemente un conjunto de creencias y actividades espirituales; cuya suprema iniciativa y sus máximas normas fueron detentadas por los mismos que manejaban los resortes de la administración. Los cargos religiosos se configuraban como un escalafón más dentro del cursus honorum, y ello determinó en gran parte que el gobierno político guardase la supremacía sobre el poder religioso, subordinándose las actividades divinas en Roma a las directrices del Senado, $\mathrm{y}$ en los Municipios a las respectivas curiae (1). El culto oficial en las diversas comunidades hispanas, en razón de las circunstancias aducidas, quedó en manos de una clase sacerdotal.que englobaba a ministros con diversas competencias, pero, dada la aludida simbiosis entre lo profano y lo religioso, con frecuencia ciertas funciones sacerdotales vinieron a ser ambicionadas, por el prestigio que conferían, como culminación de toda carrera política a nivel municipal. Es más, cuando desde el siglo II d. C., y con mayor profusión desde la tercera centuria, la elección de los magistrados civiles y religiosos quedó en manos de los decuriones, pasaron probablemente a integrarse en el seno de la curia las tres dignidades superiores del sacerdocio, (sacerdotales, pontífices y augures), como una prueba más de la identificación entre ambos poderes (2).

(1) Esta simbiosis entre lo político y lo espiritual se dio incluso en asociaciones con tanta influencia a nivel local como los collegia iuvenum. cuyos componentes participaban en todas las solemnidades religiosas de su comunidad, daban culto también con frecuencia a divinidades que coincidían con las tutelares de la ciudad, y hasta asumían un papel vigilante sobre las antiguas formas de los sacra municipales. Cfr. M. IACZYNOWSKA: "Les crganisations des iuvenes et l'aristocratie municipale au temps de l'Empire romain", en Recherches sur les structures sociales dans l'Antiquité Classique (Caen. 1970), págs. 271 s.; JdEM: «Les collegia iuvenum et leurs liaisons avec les cultes religieux au temps du Haut-Empire romain", Zeszyly Naukowe (Torun, 1968), páginas 23-44.

(2) Así lo vemos en el album decurional de Timgad (CIL, VIII, 2403; I. L.S., 6122), fechado en el 363 d. C., en el cual los sacerdotes figuran por delante de los magistrados, e incluso del propio curator designado por el emperador. Falta, sin embargo, tal mención en otro album anterior, el de Canusium (223 d. C.), quizá, según L. TANFANi (Contributo alla storia del municipio romano, Roma, 1970, pág. 245), porque en las ciudades itálicas los sacerdotes no formaban parte de la curia. Antes de que la elección de los sacerdotes hubiese quedado definitivamente como competencia exclusiva de los decuriones, la cuestión había estado regulada de modo sensiblemente diferente. El estatuto colonial de Urso (cap. LXVI) estableció que los primeros pontífices y augures de la ciudad (en sendos colegios de tres miembros cada uno) debían ser nombrados por el deductor oficial o su representante (cfr. lo que con respecto a Capua dice Cicerón: De Leg. Agr.. II, 35, 96: huc isti decemviri cum IJO colonorum ... deduxerint, centum decuriones, decem augures, sex pontifices constituerint). Las designaciones ulteriores quedaban fijadas mediante un sistema electivo comicial (cap. LXVIII) similar al utilizado para escoger los magistrados locales, tarea de la 
Nuestro objetivo esencial en el presente trabajo consiste en fijar algunas ideas generales sobre el modo de integración de las funciones sacras en los diversos tipos de carreras honorificas municipales, por lo cual descartamos, en principio, toda aquella documentación epigráfica en la que se citan individuos que únicamente revistieron cargos religiosos, sin desempeñar puestos en la administración local. Consideramos necesario, además, hacer previamente ciertas observaciones. Por lo pronto, el panorama que vamos a presentar refleja la situación interna de las comunidades hispanas en una fase de plena latinización y desarrollo de sus estatutos locales, es decir, con el disfrute de un cuadro completo de magistraturas al modo romano. Más problemático, en razón de las limitaciones epigráficas, resulta buscar testimonios que nos indiquen, a partir de casos concretos, el modo real en que las estipulaciones de los estatutos de Urso, Malaca y Salpensa se llevaron a efecto. En otro lugar (3) hemos mostrado ciertas reservas al respecto, pues consideramos probable, al menos como "hipótesis de trabajo", que ulteriores investigaciones pueden confirmar o negar, un hecho: que los reglamentos municipales hispanos, en lo que nos ha sido dado conocer, reflejan una realidad "oficial» que en la práctica debió acomodarse a las circunstancias sociales y económicas de cada localidad. Esto resulta difícil de comprobar para una época, como la que bascula entre los últimos decenios republicanos y los primeros del siglo I d. C., que nos ha dejado una limitada semblanza epigráfica. Es más, dicha parquedad documental nos impide casi por completo

que debían encargase los duunviros o prefectos, como una prueba más del control tenido por el poder político sobre el religioso. La evolución que observamos desde el siglo 11 d. C. tiende a dejar tal renovación en manos de la curia local. Esto ocurrió lentamente, pero con seguridad, y, antes de desentenderse totalmente de estas actividades, todavía le quedó al populus la oportunidad, meramente intrascendente, de dar su tácita aprobación a las determinaciones del ordo. Algunas inscripciones, para indicar esta doble intervención de un consejo comunal que designa, y un populus que normalmente se limita a dar el visto bueno a lo que se le presenta como algo definitivo, recurren al verbo conspiro, que, aunque signifique «unirse», "concertarse», "ponerse de acuerdo", no puede hacer pensar que la curia solicitara ni la venia ni la opinión de la asamblea popular. Simplemente era un modo de indicar que se tenía presente a la asamblea ciudadana de alguna manera, algo así como una concesión formularia. Una lápida de la ciudad italiana de Petelia (CIL, X, 112), de época de Trajano, ilustra claramente este estado de cosas: Imp(eratori)... Q. Fidubius... ob honor(em) Aug(ustalitatis) quem primus omnium post K(alendas) Aug(usti) a senatu conspirante populo accipere meruit, bisellium ex d(ecreto) d(ecurionum)... Sin embargo, este limitado intervencionismo popular acabará por desaparecer, y así, por ejemplo, la Valeria Situllina de un epígrafe de Cartima (5488) será estrictamente sacerdos perpetua d(ecreto) d(ecurionum) m(unicipii) C(artimitani) f(acta).

(3) J. F. Rodríguez NeILA: "Observaciones en torno a las magistraturas municipales de la Bética romana», I Congreso de Historia de Andalucía, Córdoba, 1978, páginas 203-210. 
rastrear el proceso de desenvolvimiento inicial de tales leges en el seno de unas sociedades municipales que, rigiéndose por moldes romanos, englobaban a muchos individuos que aún no disfrutaban de la civitas Romana. De haber ocurrido lo contrario, probablemente nos hubiéramos encontrado una situación diferente a la que se patentiza a través de una epigrafía, como la de "temática administrativa municipal», que corresponde esencialmente a la segunda mitad del siglo I d. C. y a la época de los Antoninos, o sea, con posterioridad al gran proceso de promoción efectuado por los Flavios.

Lo que se trasluce en este último período es, precisamente, que quienes accedían a los cargos sacerdotales en las ciudades procedían siempre de la clase social más distinguida, no solamente por su estatuto personal de ciudadanos romanos, sino también por su fortuna, necesaria siempre para pagar las summae estipuladas en el momento de asumir el puesto, o para afrontar las liberalidades siempre esperadas. Según los cálculos de EtIENNE (4), de 103 inscripciones de sacerdotes municipales, un total de 99 (un 96,11 por 100) portan los tria nomina, acompañados de la indicación de filiación y tribu. Se trata, pues, de una mayoría abrumadora de ciudadanos romanos, que se hace prácticamente total en el caso del flaminado provincial. No supone esto una absoluta marginación de la población indígena cara a las funciones religiosas, sino más bien una romanización progresiva, ya que ciertos cognomina indican la ascendencia autóctona de algunos de tales sacerdotes. No obstante, como sigue observando dicho autor, lo más natural es que las familias que aportan candidatos a los cargos religiosos estén ya desde mucho tiempo latinizadas y, bien por orgullo o por interés, hayan tomado para entonces nombres totalmente romanos. Pero esta misma deducción es, en cierto modo, una consecuencia que se puede sacar a partir de testimonios epigráficos relativamente posteriores a aquella etapa primera en que, por ejemplo, determinadas localidades béticas recibieron estatutos coloniales o municipales contando con una población autóctona que, incluso en sus estratos sociales mejor considerados, aún no había conseguido una plena integración romanizadora.

Otro aspecto que también conviene tener en cuenta, antes de desarrollar ulteriormente el tema que nos ocupa, concierne a la rigidez con que frecuentemente se observan las diversas etapas que con.

(4) R. Etrenne: Le culte impérial dans la Péninsule Ibérique d'Auguste a Dioclétien, París, 1974, pág. 223. 
figuran el cursus honorum, al menos a escala municipal. No hay un esquematismo general, que es el proceso que, de modo teórico, reflejan algunos de los reglamentos locales citados, sino una cierta variedad de carreras honoríficas, que obedecen lógicamente a las circunstancias personales de quienes las ejercieron, las cuales desconocemos casi totalmente. Y esta ausencia real de uniformidad plantea interrogantes generalmente difíciles de despejar, que no sólo corresponden al individuo que, por determinadas razones, no progresó en el cursus honorum más allá de ciertas cotas, sino a aquel otro que asumió todas las magistraturas que podía ofrecerle su ciudad, pero lo hizo siguiendo un orden que a veces no se ajusta a la gradación de dignidades y. responsabilidades inherentes a cada función. Y esto puede aplicarse por igual a los cargos civiles y a los de carácter religioso. Frente al cursus honorum prototípico, lo que se dan son diversos esquemas, unos más frecuentes que otros, lo que puede apuntar a ciertas constantes, pero siempre con un margen abierto a una pluralidad de situaciones personales $\mathrm{y}$, probablemente, de circunstancias peculiares en cada comunidad. Esta inobservancia de normas fijas que, al menos en teoría, se tradujeron en disposiciones oficiales, se hace patente también en aspectos concretos de la legislación relativa a las condiciones personales necesarias para revestir una función administrativa.

Por ejemplo, ¿a qué edad se podía desempeñar un sacerdocio municipal? Este requisito debía variar con los individuos, aunque, por constituir tanto los cargos administrativos como los sacerdotales el cursus honorum, lo más natural es que nadie pudiera alcanzar un sacerdocio antes de la edad mínima legal para desempeñar una magistratura, cifrada por término medio en los veinticinco años (5). Es difícil también saber si en esta materia se dieron las mismas irregularidades que conocemos con respecto al decurionado. Las inscripciones aportan poca información en cuanto a la edad. El flaminado, por ejemplo, que solía culminar cualquiera carrera política

(5) En Italia la edad mínima estuvo fijada en treinta y un años (para la cuestura estatal) en tiempo de Sila, y luego en treinta años, cifra establecida por Pompeyo para las ciudades bitinias, pero Augusto modificó tales disposiciones poniendo el límite en los veinticinco (Dro CAS., LIV, 7), generalizándose este uso posteriormente. Así lo indica tácitamente UlPiano (Dig., L, 4, 8): "No debe admitirse a los menores de veinticinco años en la administración de las ciudades, ni en las cargas que no son patrimoniales, ni en los cargos municipales; tampoco pueden ser decuriones, y, si lo son, no tienen voto en la curia decurional». Cfr. Dig., L, 5, 2; Plin., Ep., X, 79 y 80. En pocos casos los menores fueron presentados como candidatos, y nunca por su propio conducto, sino tomando sus padres la responsabilidad de tal decisión (cfr. Dig., $\mathrm{XV}, 1,3)$, especialmente en lo relativo a la conservación del patrimonio público. 
municipal (edilidad más duunvirato), no se debía ocupar antes de los treinta años. Conocemos, no obstante, el caso de un ascenso meteórico, el de Q. Calpurnius Flavus, que murió en Barcino con veintinueve años (4523). Antes de recibir por decreto decurional los honores flaminales a título póstumo (post mortem), había ocupado las más altas magistraturas (6). Más sorprendente aún es el testimonio que nos aporta Postumia Aprulla, flaminica de Saetabis con sólo diecinueve años (Mandor, 3782). M. Fabius Probus, al fallecer con treinta y ocho años en Aurgi (3362), había sido ya flamen de la ciudad y pontifex perpetuus divor(um) et Aug(ustorum)? Otro ejemplo de carrera fulgurante vino a ser la de L. Valerius Optatus. Cuando murió con treinta y cinco años había ejercido como edil, duunviro, flamen y magister saliorum en Saguntum (6055). Podemos citar además a Aelia Apra, oriunda de Aratispi, pero que murió en Urso (5443) a los treinta y cinco años también, siendo por entonces sacerdos perpetua de la colonia (siglo II d. C.).

Los demás testimonios que tenemos al respecto nos dan edades ya altas en las que es más natural que se desempeñasen funciones sacerdotales, quizás desde mucho antes, por parte de las personas citadas en las lápidas: seviro de setenta años (Aurgi, 3363); seviro de sesenta y tres (Gades, 1734); flaminica de sesenta y uno (Sacili Martiales, 2188); seviro de sesenta (Arcos, 1363); seviro de cincuenta y tres (Gades, 1733). No obstante, las excepciones apuntadas demuestran la irregularidad en el desarrollo de las carreras honoríficas municipales, que en lo concerniente a la aetas podría confirmarse también con ejemplos alusivos únicamente a las funciones administrativas. $\mathrm{Y}$ tales circunstancias afectan igualmente a la ubicación dentro del cursus honorum local de los dos sacerdocios más destacados que podían ejercerse, el flaminado y el pontificado.

\section{EL FLAMINADO Y LAS CARRERAS ADMINISTRATIVAS LOCALES}

Comenzando nuestro análisis por aquellas trayectorias administrativas locales dentro de las cuales se imbricó el cargo de flamen, queda en principio corroborada la impresión de ÉTIENNE (7), para quien son mucho más frecuentes las carreras mixtas que aquellos casos en que el individuo ejerció únicamente el flaminado. En efec-

(6) Cfr. R. Etienne: Op. cit., pág. 238.

(7) Idem, págs. 224-229. 
to, de 74 inscripciones hispanas en las que son mencionados flamines, sólo en ocho de ellas los personajes citados han desempeñado el flaminado sin más (un 10,81 por 100 del total), mientras que en las 66 restantes $(89,18$ por 100$)$ aparecen, conjuntamente con tal dignidad sacra, otras funciones civiles y religiosas. No obstante, la secuencia de tales magistraturas y sacerdocios no responde siempre a un esquema uniforme, perfilándose diferentes variantes que arrojan los siguientes porcentajes:

\begin{tabular}{|c|c|c|c|}
\hline Núm. & TIPOS DE CARRERAS & Total & Porcentaje \\
\hline 1 & Sólo FLAMEN ........ & 8 & $10,81 \%$ \\
\hline 2 & DUUMVIR + FLAMEN $\ldots \ldots \ldots$. & 22 & $29,72 \%$ \\
\hline 3 & EDIL + DUUMVIR + FLAMEN $\ldots \ldots \ldots$ & 20 & $27,02 \%$ \\
\hline 4 & EDIL + CUESTOR +DUUMVIR + FLAMEN $\ldots$ & 5 & $6.75 \%$ \\
\hline 5 & DUUMVIR + FLAMEN + PONTIFEX ... ... & 3 & $4,05 \%$ \\
\hline 6 & EDIL + FLAMEN $\ldots \ldots \ldots \ldots$ & 2 & $2,70 \%$ \\
\hline 7 & EDIL + FLAMEN + DUUMVIR + PONTIFEX & 2 & $2,70 \%$ \\
\hline 8 & EDIL + DUUMVIR + FLAMEN + QUIN- & & \\
\hline & QUENAL + PONTIFEX $\ldots \ldots \ldots \ldots$ & 2 & $2,70 \%$ \\
\hline 9 & $\begin{array}{llllllllllll}\text { VARIOS } & \ldots & \ldots & \ldots & \ldots & \ldots & \ldots & \ldots & \ldots & \ldots & \ldots & \ldots\end{array}$ & 10 . & $12,16 \%$ \\
\hline
\end{tabular}

Destaca ante todo el elevado índice de quienes han alcanzado el flaminado sin haber pasado por la edilidad, directamente desde el duunvirato, cometido público que les ha servido por tanto de trampolín para dicha función religiosa. Contrastado este hecho con la pequeña cantidad de quienes ejercieron como flamines sin haber sido previamente promocionados por ninguna magistratura, resulta evidente que el desempeño de los honores municipales de carácter civil era la mejor garantía para ser designado flamen por la curia, lo que debía constituir para muchos el objetivo supremo de su cursus honorum, que una vez conseguido dignificaba al individuo antes incluso de iniciar oficialmente sus actividades como tal (8).

(8) Entre el momento de la elección y el de la efectiva toma de posesión debía transcurrir un cierto tiempo, por lo que en algunas inscripciones designatus viene a ser el modo de indicar que un sacerdote, habiendo sido ya designado para el cargo. no había aún empezado a ejercerlo efectivamente. L. Aufidius Celer Masculinus, natural de Flaviaugusta, marchó en un determinado momento a Tarraco, donde fue clegido flamen. La $r$ (es) p(ublica) s(ua) no esperó a que su compatriota asumiese definitivamente el cargo para honrarle con una inscripción, d(ecreto) d(ecurionum), por lo que en la lápida tarraconense en cuestión Aufidius Celer es denominado flamen designatus (4.196). Caso similar es el de un tal M. Clodius, natural de Ipsca (1.570), donde vivió en la época de Vespasiano. En un epígrafe aparece, juntamente con sus hijos, honrando a la domus Augusta y mostrando su reconocimiento por ser pontifex designatus. Igualmente los términos sacerdotalis y pontificalis indican que aún no se detenta la función, aunque se está designado para ella. Estas lápidas se han levan- 
Dicho proceso era natural y consustancial con la misma esencia monopolística del poder cívico-religioso que estuvo depositado en manos de los núcleos aristocráticos municipales, quienes consideraban que tanto la ejecución de las actividades administrativas como la realización del culto público exigían una dignitas que se estimaba como algo inherente a sus personas. Ambos aspectos de la vida oficial ciudadana se integraban, por tanto, dentro de un mecanismo casi cerrado de dominio, de acuerdo con el cual un duunviro, al cesar en su anualidad, pasaba a integrarse entre los decuriones, los cuales normalmente elegían para los más altos cargos religiosos a quienes de entre ellos tenían ya conocimiento previo en temas de gobierno. Y no se cuestionaba que la experiencia adquirida en materia civil podía perfectamente aplicarse en muchos aspectos a un cargo religioso. Ello aparte de que los decuriones eran generalmente miembros de las más ricas familias municipales y los más capacitados para afrontar, por ambición y posibilidades personales, los numerosos gastos que suponían las liberalidades propias del flaminado (9).

tado siempre por un motivo especial que explica la premura de los homenajes sin haber aún los interesados accedido al cargo. Dos epígrafes de Acinipo nos ilustran adecuadamente la cuestión. En uno de ellos (1348) un cierto M. Marius Fronto aparece como pontificali(s), habiendo ocupado antes el duunvirato. Es la pleps quien le honra ob merita, y tal impaciencia tiene su razón de ser, ya que Maritus era patrono de la ciudad y, en razón de tal expresión, de aquellos que no se limitaban únicamente a ostentar el título. El otro testimonio (1349) se refiere a un tal $Q$. Servilius Lupus, presentado como pontificalis, sin ninguna otra mención de cargos administrativos. Su valimiento hacia la comunidad no estuvo predeterminado, pues, por una función política que le permitiera favorecer a Acinipo. Es uno de esos patronos que, según L. HaRmand (Le patronat sur les collectivités publiques des origines au BasEmpire, París, 1958, págs. 314-318), surgieron en el seno de los sectores dirigentes municipales, y cuya mejor carta de presentación, que les atrajo siempre el favor de las masas populares, fue su fortuna, invirtiendo parte de ella en liberalidades públicas. Servilius porta, sin embargo, una tribu, la Maecia, poco frecuente en Hispania, lo que hace pensar que quizá no fuese oriundo de la misma Acinipo.

(9) Conviene tener en cuenta que en un aspecto tan sustancial como cl sostenimiento económico, las dependencias entre la esfera civil y la religiosa eran estrechas. Según Cicerón (Div., XIII, 2), en los Municipios era competencia del tesoro comunal atender a los gastos del culto público, y la Lex Ursonensis (cap. LXIX) establece claramente cómo los magistrados debían ocuparse de los suministros necesarios para los sacrificios y demás ceremonias cultuales de los sacra, actividades en las cuales quedaban a su vez sometidos a la supervisión de la curia. Idéntico procedimiento regía para la elaboración del calendario festivo (Lex Urs., cap. LXV). La administración de los lugares sagrados era también una tarea laica, de la que quedaban excluidos los sacerdotes. Ya se tratase de rentas accidentales de los templos, o bien de las cantidades destinadas a tal efecto, lo cierto es que la autoridad civil era la encargada, tanto de la recaudación como de los dispendios. Una prueba taxativa de ello lo tenemos en la Lex Furfensis (58 a. C.), donde se distinguen por un lado el templo, y por otro los bienes-raíces que le son adscritos (CIL, I, 603). Estos últimos son de carácter eminentemente profano, mientras que el templo conserva su sacra condición. Si se presenta la ocasión de venta o alquiler de dichos bienes, toda la jurisdicción 
Precisamente esa fortuna permitía a muchos notables municipales obtener la elección para el duunvirato sin haber pasado antes por la edilidad. Bien es verdad que el ejercicio favorable de este último cargo podía suponer un buen punto de partida para quien aspirase a más altas cotas honoríficas, pero no es por ello menos cierto que, a veces, la gestión edilicia, si se encontraba con problemas o tenía en contra la opinión pública, podía "quemar» políticamente a quien la detentase (10). Lógicamente el acceso directo al duunvirato eliminaba un primer escalafón, que quedaba así circunscrito a "etapa de promoción política» para aquellos munícipes que no disponían ni del prestigio personal ni del nivel económico exigibles a quienes se sentían suficientemente respaldados para iniciar su trayectoria pública con el cargo de duunviro. Dar este paso suponía optar en menos tiempo al flaminado, y ello explica que sólo en contados casos (11) veamos a los ediles revestir inmediatamente tan alta dignidad sacra, y, por el contrario, cómo entre los flamines fue el esquema DUUMVIR + FLAMEN el más repetido, siendo su distribución la siguiente:

\section{LUSITANIA.}

- $($ Pax Iulia, 49$)=$ Duumvir + Flamen Ti. Caesaris Aug.

- $($ Pax Iulia, 53$)=$ Duumvir + Flamen divorum.

- $($ Ossonoba, 5141$)=$ Flamen + Duumvir.

corresponde a los ediles. Los bienes-raices adquiridos con dicho dinero revisten un carácter religioso, dado el objetivo para el que son destinados. Los magistrados pueden aplicar a los gastos de culto los fondos adecuados, sin que el sacerdote pueda nunca utilizar directamente y en su provecho la fortuna de los recintos sacros. También podía recurrirse para atender las necesidades ordinarias a las rentas propias de los colegios sacerdotales, a cada uno de los cuales se solía asignar a veces una porción del ager de la ciudad.

No obstante, una parte importante de las cantidades destinadas a este capítulo procedia de las summae honorariae que todos los sacerdotes y demás funcionarios adscritos al servicio religioso debían aportar cuando asumían el cargo, siendo administrados tales caudales por la curia. Se admitía, de todas formas, la exención de tal pago, pues ocasionalmente los epígrafes indican que los honores fueron revestidos de modo gratuitus (CIL, V, 6431).

(10) No olvidemos que, significativamente, ningún edil hispano atestiguado epigráficamente, a diferencia de sus colegas de grado superior, fue reelegido para el cargo. Cfr. J. F. Rodrícuez NeILA: "Las elecciones municipales en la Bética romana". I Congreso de Historia de Andalucía, Córdoba, 1978, pág. 174.

(11) La justificación de tales excepciones puede ser estrictamente pecuniaria. Ta. les aediles bien pudieron destacar por sus munificencias, ya financiando juegos o monumentos. y no hay que olvidar que desde Augusto recayó sobre los flamines la responsabilidad de sufragar y organizar los ludi municipales (SUET.: Vit. Aug., LIX). Cfr. CIL, II, 5523 (Corduba): edito ob honorem flaminatus munere gladiatorio et duabus lusionibus; Lex Urs., cap. CXXVIII, citándose entre las obligaciones de los magistrados. 
2. BETICA.

- $($ Malaca, 1979$)=$ Flamen divi Aug. + Duumvir.

- $(U c c u b i, 1558)=$ Duumvir + Flamen Rom. et Aug.

- (Barbesula?, 1941) = Duumvir + Flamen perp.

\section{TARRACONENSE.}

- $($ Tarraco, 4267$)=$ Flamen + Duumvir (en dos ciudades $)$.

- $($ Tarraco, 4264) $=$ Duumvir + Flamen.

- $($ Tarraco, 4211$)=$ Duumvir + Flamen perp.

- $($ Tarraco, 4217$)=$ Duumvir + Flamen.

- $($ Valeria, 3179$)=$ Duumvir + Flamen Rom. et Aug.

- $($ Castulo, 3276 $)=$ Duumvir + Flamen Rom. et Aug.

- (Castulo, 3277) $=$ Duumvir + Flamen perp.

- (Castulo, H.A.E., 8-11, 1466) = Duumvir + Flamen Rom. et Aug.

- (Villajoyosa, 3571) = Duumvir ter + Flamen quat.

- (Saetabis, 3620) = Duumvir + Flamen divi Aug.

- (Saetabis, 3623) = Duumvir + Flamen Rom. et Aug.

- $($ Liria, 3789 $)=$ Duumvir + Flamen.

- $($ Liria, 6014) $=$ Duumvir bis + Flamen bis.

- (Huesca, . H.A.E., 12-16, 2211) = Duumvir + Flamen.

- $($ Barcino, 4516$)=$ Duumvir + Flamen Rom. et Aug.

Hay que destacar, por lo pronto, el predominio absoluto de la Tarraconense y el equilibrio de Lusitania y Bética en cuanto a número de casos en el presente esquema. Ello cuadra bien con el hecho de que en las dos primeras Provincias imperiales, el culto a la casa reinante y a los divi alcanzó más altas cotas, mientras que en la Bética, circunscripción senatorial, se impulsó algo más tardíamente. Se observa también cómo en algunas de las inscripciones citadas el flaminado precede a la magistratura duunviral. Ello podría haber sido una excepción, explicándose por el hecho de que el prestigio alcanzado por el ejercicio del flaminado servía para, posteriormente, tener buena baza con vistas a los puestos de responsabilidad administrativa. No obstante, si tales testimonios constituyen una excepción, deben serlo en otro sentido. Como se ve, la mayoría de las veces el corto, pero enjundioso cursus, se expone en las inscripciones con la sucesión cronológica de los cargos de que el interesado ha sido investido, y luego su meta final, el flaminado. 
Pero tampoco puede extrañar que a veces el cursus se dispusiera en orden inverso, para poner de relieve en primer lugar cuál era el cargo más importante desempeñado por el individuo allí citado, el que constituia el principal exponente de su orgullo, el que había colmado su ambición pública.

Dado que la edilidad era, igualmente, en muchos casos el primer peldaño con el que numerosos munícipes iniciaban su carrera política local, pudiendo aumentar sus méritos cara al futuro durante su gestión, es también normal que el esquema EDIL + DUUMVIR + FLAMEN figure a renglón seguido en frecuencia. Algunos de estos testimonios evidencian cómo ciertos ediles, merced a las liberalidades dispensadas durante su mandato, alcanzaron el flaminado antes que el duunvirato. Pero en ningún caso se constata que dicha dignidad religiosa precediera a las otras dos magistraturas. La distribución de los ejemplos es como sigue:

\section{LUSITANIA.}

- (Olisipo, 194) $=$ Edil + Duumvir + Flamen Germ. Caesaris + Flamen Iuliae Aug.

2. TARRACONENSE.

- (Ilerda, 3010) $=$ Edil + Duumvir + Flamen.

- (Ilerda 5848$)=$ Edil + Duumvir + Flamen.

- $($ Ilerda, Lara, 5$)=$ Edil + Duumvir + Flamen.

- (Albarracín, 3174) = Edil + Flamen + Duumvir.

- $($ Barcino, 4521$)=$ Edil + Duumvir + Flamen.

- $($ Barcino, 4524 $)=$ Edil + Duumvir + Flamen.

$-($ Barcino, 4524$)=$ Edil + Duumvir bis + Flamen.

$-($ Barcino, 4525$)=$ Edil + Duumvir + Flamen Aug.

- $($ Barcino, 6150$)=$ Edil + Duumvir + Flamen.

- $($ Barcino, 6151 $)=$ Edil + Duumvir + Flamen.

- (Barcino, H.A.E., 8-11, 559) = Edil + Duumvir bis + Flamen Divor. et Aug.

- (Gerunda, 4622) $=$ Edil + Duumvir + Flamen.

- (Aytona, Lara, 32) = Edil + Duumvir + Flamen Aug.

- (Isona, Lara, 312) = Edil + Duumvir + Flamen:

- (Ebusus, 3662) = Edil + Duumvir + Flamen.

$-($ Mago; 3709$)=$ Edil + Duumvir + Flamen Divor. et Aug. 
- (Saguntum, 3860) $=$ Edil + Duumvir + Flamen.

- (Saguntum, 6055) $=$ Edil + Flamen + Duumvir .

- (Emporiae, IAGIL, 3) = Edil + Duumvir + Flamen.

- (Alcudia, 3696) $=$ Edil + Duumvir + Flamen Rom. et Aug.

La notable repetición de los dos esquemas indicados hasta ahora, con apreciable diferencia sobre los demás, demuestra en cierto modo cómo el cursus honorum municipal, aun ofreciendo una relativa variedad de situaciones, obedecía sustancialmente a una especie de "sucesión estereotipada", probablemente fijada de modo oficial en los estatutos iniciales de muchas comunidades, pero ulteriormente condicionada por las circunstancias peculiares de cada ciudad, e incluso por las motivaciones personales de quienes en su seno constituian el círculo dirigente. De acuerdo con tal modelo teórico, un edil tenía de modo oficioso bastantes posibilidades de resultar luego elegido duunviro, y éste a su vez tenía una importante opción para ser flamen. Otras magistraturas, como la prefectura o la quinquenalidad, no pueden ser ubicadas con regularidad en el cursus honorum, si bien la primera, por las circunstancias excepcionales en que regía, debía recaer en individuos con experiencia pública previa, y la segunda, por sus particulares responsabilidades (así la confección del album decurional) exigía una dignidad sólo consolidada tras una completa trayectoria municipal. Pero existen, desde luego, casos peculiares.

También era bastante factible que un hijo repitiese, si se dedicaba a la vida pública, el mismo cursus honorum que su padre hasta mejorándolo en lo que se refiere a reiteración de algunos de los cargos (Barcino, 4524). Se observa, del mismo modo, cómo en determinadas ciudades (Tarraco, Barcino, Castulo) privaban unos particulares esquemas; así el número 2 se da con cierta frecuencia en Tarraco y Castulo, donde no hay constancia del número 3, que, sin embargo, priva en Ilerda y, sobre todo, en Barcino. Son las ciudades de la Tarraconense, como era de esperar, las que se hallan siempre a la cabeza.

Aunque la dirección de los fondos municipales fue encomendada a los duunviros en muchas ciudades, siempre bajo la supervisión de la curia, en varias comunidades existió la cuestura al frente del erario público. Esta magistratura conformaba un cargo más en el escalafón administrativo local, que unas veces podía desempeñarse después de la edilidad, y antes del duunvirato o flaminado, y otras 
después de haber cubierto todas las funciones anteriormente citadas. Los casos que encontramos corresponden a la Tarraconense, y destaca, precisamente, el hecho ya reseñado de que en tres de las cinco lápidas que mencionamos a continuación la cuestura sea ubicada al final. Orden inverso no existe, puesto que la edilidad es citada al principio y, por tanto, de haberse dado aquél, la cuestura hubiera iniciado un cursus culminado con la edilidad ejercida tras el duunvirato, lo que resulta imposible. Incorrecciones en el orden de sucesión de los cargos son poco probables. Cabe pensar, pues, que o bien esta magistratura, por la especial responsabilidad financiera que entrañaba, era reservada para el final del cursus, una vez que el interesado hubiese dado pruebas de capacidad, experiencia y fidelidad durante el ejercicio de las anteriores funciones profanas y religiosas (12); o que se aceptaba su desempeño como un munus (13). Las dos posibilidades caben en el marco variado de los estatutos locales. Los testimonios al respecto, todos correspondientes a la Tarraconense, son:

- (Tarraco, 4212$)=$ Edil + Cuestor + Duumvir + Flamen divi Titi.

- (Tarraco, 4224) $=$ Edil + Cuestor + Flamen Rom. et Aug. + + Duumvir.

- (Saguntum, 3864) $=$ Edil + Duumvir + Flamen bis + Cuestor.

- (Saguntum, 3865) $=$ Edil + Duumvir bis + Flamen bis + Cuestor.

- (Mascarell, 4028) = Edil + Duumvir + Flamen Aug. + Cuestor.

(12) A los magistrados se les exigían ciertas garantías pecuniarias al asumir el cargo: Lex Mal., cap. LX: Qui in eo municipio duumviratum quacsturamve petent quique propterea, quod paucio $[r]$ um nomine quam oportet professio facta esset, nominatim in eam condicionem rediguntur, ut de his quoque suffragium ex hac lege ferri oporteat, quisque eorum, quo die comitia habebuntur, ante quam suffragium feratur, arbitratu eius qui ea comitia habebit, praedes in commune municipum dato pecuniam conmunem eorum, quam in honore suo tractaverit. salvam is fore. Cfr. también cap. LXVII. Observamos cómo en todos los testimonios epigráficos alusivos a cuestores se trata de individuos que han tenido una prolongada experiencia política en su comunidad, desempeñando como mínimo tres funciones civiles o religiosas. Con notable frecuencia la quaestura ha culminado la carrera honorífica de un notable local, lo que da a dicha magistratura una consideración superior muy por encima de la secundaria que en los estatutos municipales recibe respecto al duunvirato. Incluso en determinadas ocasiones (Saguntum, 3864-3865) la cuestura ha sido revestida por quienes demostraron antes una alta cualificación para las funciones públicas. eierciendo más de una vez algunas de ellas, y distinguiéndose por su honradez y capacidad en el manejo de los fondos comunales. No hay que olvidar que, puesto que el erario decurional atendía también los gastos religiosos. quizá no sea una castialidad que casi todos los quaestores conocidos fuesen elegidos tras una trayectoria previa en los puestos civiles y religiosos. Sólo excepcionalmente (Tarraco, 4212-4224) se respetó la sucesión teórica que hacía de la cuestura el escalafón siguiente a la edilidad.

(13) A. D’Ors: Epigrafía Jurídica de la España Romana, Madrid, 1953, pág. 145. 
Si de la edilidad, como hemos visto, era factible acceder directamente al flaminado, eran muy raras las veces en que el duunvirato no se revestía a continuación. Sólo tenemos dos casos con el esquema número 6 (EDIL+FLAMEN), uno en Saguntum (3856) y otro en Barcino (6321). Y como esquemas también excepcionales, pero que indudablemente nos presentan a los personajes con más alto prestigio, más demostrada experiencia y más notable fortuna en la vida local, tenemos las siguientes carreras municipales, ciertamente muy completas, en las que se integra, además del flaminado, el pontificado:

Núm. 5. DUUMVIR + FLAMEN + PONTIFEX.

- (Obulco, 2132) = Duumvir + Flamen + Pontifex.

- (Urgavo, 2105) $=$ Duumvir bis + Flamen sacr. pub. + Pontifex domus Aug.

- $($ Corduba, 5523$)=$ Pontifex + Flamen perp. + Duumvir.

Núm. 7. EDIL + FLAMEN + DUUMVIR + PONTIFEX.

$-($ Obulco, 2126) $=$ Edil + Flamen + Duumvir + Pontifex.

- $($ Obulco, 2129) $=$ Edil + Flamen + Duumvir + Pontifex.

Núm. 8. EDIL + DUUMVIR + FLAMEN + QUINQUENAL +

+ PONTIFEX.

- (Ulia, H.A.E., 6-7, 1023) = Edil + Duumvir + Flamen divor. Aug. + + Quinquenal + Pontifex sacror. perp.

- (Carthagonova, BRAH, 1908; p. 505) $=$ Edil + Duumvir + Flamen August. + Quinquenal + Pontifex.

La mayor parte de estos ejemplos corresponde a la Bética, donde el pontificado estaba más arraigado (14), pudiendo incluso alcan. zarse como suprema aspiración. Esta situación culminante en el cursus honorum indica que la dignidad del pontifex no desmerecía por su estimación y atributos al lado del flaminado, ejercido en numerosas ocasiones con anterioridad al pontificado. En la Provincia meridional, por tanto, ser flamen no constituía, en tan alto grado como en la Tarraconense y Lusitania, la meta superior de cualquier notable local. Sí notamos en estos tipos de carreras honoríficas, cada vez más complicadas, que con mucha frecuencia el cursus honorum se abre con magistraturas civiles, no con cargos religiosos (por lo cual el orden que vemos en la lápida 5523 de Corduba debe considerarse inverso), y que, cuando la trayectoria política del indi-

(14) Cfr. Lex Urs., cap. LXVI-LXVIII. 
viduo se desarrolla a lo largo de toda la gama honorífica que le ofrece su ciudad, se patentiza una cierta alternancia en el ejercicio de las funciones de uno u otro tipo. Resulta, no obstante, lógico que la quinquenalidad, que venía a ser el escalafón administrativo de más responsabilidad en la vida pública municipal, fuese detentada sólo por quienes tenían ya una larga experiencia, tras haber pasado por casi todas las tareas profanas y sacras. Existen, no obstante, contadas excepciones.

Por otra parte, es posible que dicha alternancia, limitándonos solamente al capítulo de las competencias sagradas, abarque dos áreas claramente definidas. Sabemos que revestir el flaminado no supone exclusivamente dedicarse al culto imperial, y ser sacerdos o pontifex no significa estar ceñido exclusivamente a los sacra de la ciudad (15). Hay una cierta flexibilidad en las titulaciones, y de hecho solamente aquellas que complementan a la denominación de flamen o pontifex con otros detalles permiten hacer una exacta clasificación. Sin embargo, a partir de algunos ejemplos epigráficos recogidos en los apartados números 5-7-8, y otros casos citados infra, quizás se apunte una cierta tendencia, en el sentido de que quien lograba revestir sucesivamente el pontificado y el flaminado (en este orden o en el inverso) dentro de su cursus honorum, lo hacía ocupando uno en función de los sacra de su comunidad, y otro en atención al culto imperial, haciendo de tal modo mucho más completa su trayectoria honorífica (16). Esto se suele confirmar cuando los dos títulos van detallados. O bien basta con que lo sea uno solo, suponiéndose para el otro la esfera de competencias contraria. Más problemático, desde luego, resulta llegar a conclusiones seguras cuando el cursus cita simplemente el cargo de flamen o de pontifex sin más detalles (como vemos en Obulco).

\section{Núm. 9. VARIOS.}

En este apartado hemos reunido todos aquellos esquemas que únicamente presentan un caso, aunque incorporado siempre el fla-

(15) Aunque en teoría el pontifex estaba al cuidado de los sacra en general, también en ocasiones se nos mencionan flamines consagrados al conjunto de las matcrias sagradas, como el flamen sacr(orum) pub(licorum) municip(ii) Alb(ensis) Urg(avonis) que conocemos por un epigrafe de dicha ciudad (2105). Del mismo modo, la factible cquivalencia entre los títulos y competencias del flamen y del sacerdo:; quizá queda apuntada en la lápida de Valeria Paetina, natural de Tucci, que se cita como flami. nica sive sacerdos municipi Castulonensis (3278).

(16) Así en Urgavo, 2105; Ulia, H. A. E., 6-7, 1023; Carthagonova, BRAH, 1908, página 505 . 
minado. Su variedad es, ciertamente, notable, pero también se dan en ellos carreras muy concretas. Precisamente el bajo número de éstas, siendo más corrientes los esquemas simples DUUMVIR + + FLAMEN o EDIL + DUUMVIR + FLAMEN, muestra sobradamente cómo el llegar al copo de todas las funciones civiles y religiosas en el ámbito municipal no estaba al alcance más que de las personalidades más excepcionales. Excepcionales, por lo menos, a nivel local, ya que, aunque para nosotros sean hoy casi meros nombres en unas lápidas más o menos corrientes que nos han conservado su recuerdo, en el momento que les tocó vivir es indudable que fueron celebridades dentro de su comunidad, y las opiniones suyas fueron también las de más peso, con vistas a dar a la vida pública de su ciudad cualquier rumbo en lo político o en lo sagrado. $\mathrm{He}$ aquí la relación de estas carreras municipales variadas. Como se ve, en algunos casos unos simples honores edilicios han abierto al interesado las puertas de más altas responsabilidades. En otros tan sólo se han desempeñado cargos de carácter religioso.

a) EDIL + DUUMVIR + PREFECTO + PONTIFEX + FLAMEN. - (Ulia, 1534) $=$ Edil+Duumvir + Prefecto de C. César+Praef. iter + Pontifex sacror. + Flamen divi Aug.

b) EDIL + DUUMVIR + FLAMEN + CUESTOR + PONTIFEX.

- (Saguntum, A. Ep., 1957, 314).

c) EDIL + DUUMVIR + FLAMEN + AUGUR + CUESTOR.

- (Saguntum, 4028).

d) EDIL + FLAMEN + CUESTOR.

- (Tarraco, 4279) $=$ Edil + Flamen divi Aug. + Cuestor.

e) PONTIFEX + FLAMEN + PRAEFECTUS FABRUM.

- (Aquae Flaviae, $5617=2479)=$ Pontif. perp. + Flamen perp. + praef. fabr.

f) HONORES EDILICIOS + DUUMVIR + FLAMEN.

- $($ Barcino, 4514$)=$ Consecutus in honores aedilicios + Duumvir ter + Flamen Rom. divor. et Aug.

g) PONTIFEX + FLAMEN.

- $($ Astigi, 1475) $=$ Pontif. perp. + Flamen divor. Aug.

1) DUUMVIR + FLAMEN + PONTIFEX + AUGUR.

- (Obulco, 2132).

j) MAGISTRATUS + FLAMEN.

- $($ Complutum, 3033$)=$ Magistratus + Flamen Rom. et Aug. 
Seguimos viendo cómo la mayoría de estos peculiares y poco representados esquemas se inician con una magistratura civil, normalmente la edilidad (aunque seguida casi siempre del duunvirato). Muy particulares en su estructura resultan las siguientes carreras: d) Es poco frecuente que un individuo, tras ejercer simplemente la edilidad, y sin pasar por el duunvirato, alcance no sólo el flaminado, sino incluso la cuestura, asumidas probablemente en virtud de méritos personales muy excepcionales; $e$ ) Aquí lo singular radica en el carácter perpetuo de las dos dignidades religiosas, a las que sigue una prefectura, que debe ser un cargo local más que el ecuestre de similar titulación, pero con ausencia de otros puestos administrativos. Por lo que respecta a las dignidades religiosas, quizás pueden hacerse ciertas observaciones sobre la presencia en algunas carreras del augurado (cfr. también otros esquemas citados infra). Salta a la vista que dicha función aparece normalmente en secuencias honoríficas muy completas, y es corriente que se cite en último lugar, o sea, culminando un cursus honorum. Esta circunstancia real contrasta, en principio, con el contenido teórico de Lex Urs., capítulos LXVI-LXVIII, donde los pontífices se mencionan siempre por delante de los augures, quizás apuntando a la precedencia de los primeros en la gradación honorífica. Pero en la práctica puede que tal preeminencia fuese relativa, pues no hay que olvidar la gran responsabilidad pública inherente al augurado, que seguramente exigía para quien lo detentaba una gran experiencia y honestidad probadas durante otros cargos anteriores, por lo cual se alcanzaría sólo tras una prolongada trayectoria pública (17).

\section{IIT. PECULIARIDADES DEL PONTIFICADO MUNICIPAL}

Pasemos a continuación a centrarnos en aquellos esquemas donde el flaminado está ausente, siendo el título de pontifex el más

(17) El prestigio del augurado, para quien ejercía una carrera política, radicaba esencialmente en que, no siendo incompatible con ninguna magistratura, aumentaba el valor de su gestión por la capacidad que suponía de comunicación directa y personal con lo divino (J. BAYET: Histoire politique et psychologique de la religion romaine, París, 1973, pág. 103) Cada augur desempeñaba su cometido con entera independencia, sin ninguna jefatura colegial, entendiendo en todo lo concerniente a los auspicia (Cic.: De leg., II, 8, 21). Consecuentemente, los augures tenian un gran ascendiente sobre los magistrados, acompañándolos, al igual que a los pontífices, en los actos pi. blicos más solemnes, y oponiéndose a su ejecución si los presagios resultaban desfa. vorables. En el estatuto colonial de Urso las circunstancias de su elección y renovación, así como los requisitos necesarios para el cargo (caps. LXVIII-XCI), eran ịdénticos a los del pontificado. 
corrientemente citado (18). Nos encontramos aquí también con un abigarrado abanico de posibilidades.

\section{Núm. 10. DUUMVIR + PONTIFEX.} i

Es el más repetido (once menciones), especialmente entre las comunidades de la Bética. Volvemos a insistir en que el arraigo en esta Provincia senatorial del culto imperial fue menor que en las otras dos circunscripciones hispanas. En la zona meridional pervivieron con, más solidez las magistraturas religiosas ya existentes desde antes de expandirse el culto a los Augusti y a los divi. Es probable. (y los testimonios epigráficos parecen demostrarlo) que, en tal caso, el flaminado no hubiese culminado en la Bética, a diferencia de. la Tarraconense, las aspiraciones de notoriedad de cualquier notable local. Más bien el pontificado vino a ser el objetivo supremo de quienes, pretendiendo el duunvirato sin pasar por la edilidad, esperaban alcanzar aquél a renglón seguido, o sea, ser pontifex tuvo en la Bética más prestigio y peso que en las restantes Provincias hispánicas, y es ello la causa de que este esquema número 10 venga a desempeñar aquí un papel correlativo al del número 2 en la Tarraconense' y la Lusitania; pudiéndosele aplicar similares observaciones. Los testimonios al respecto son los siguientes:

(18) Para aspirar al pontificado se exigían ciertas condiciones similares a las que debía reunir cualquier decurión o augur: no podía serlo quien domicilium in ca col(onia) oppido propiusve it oppidum p(assus) $\infty$ non habebit annis $V$ proxumis, o sca, quien no tuviese domicilio en la urbe dentro de un radio de mil pasos, o se hubiese trasladado allí desde el lugar donde residiera (Lex Urs., cap. XCI). La finalidad de este requisito era el. poder tomársele al candidato prenda de garantía suficiente (unde pignus eius quot satis sit capi possit). Desde luego, que un pontífice no dispusiera de fortuna para atender tales exigencias no debía ser corriente, dado que solían ser miembros de los sectores más acomodados, y frecuentemente se permitían obsequiar a sus paisanos, quienes les habían elegido (al menos así fue durante un período). con toda suerte de munificéncias. Algunas de las condiciones enumeradas (como tcner propiedades en la ciudad), e igualmente el ser depositario de los sacra particulares de la comunidad; hacían además del pontifex un individuo probablemente más arraigado en su localidad que el flamen, a quien competía un culto, como el impcrial, que se integraba en una realidad extramunicipal. Todo ello, claro está, salvando las concomitancias ya señaladas entre ambas dignidades. La proyección pública del pontífice sobre la vida religiosa de los munícipes tenía numerosas ocasiones para manifestarse, al margen de aspectos teóricos. Un ejemplo claro era la coercitio, que englobaba el ius multae dicendae (poder similar entre los magistrados, según Lcx Mal., cap. LXVI) y, en ciertos casos, el ius vitae necisque, con referencia a las materias sagradas, facultad que podía dirigirse contra cualquier ciudadano contraventor de las disposiciones correspondientes (cfr. A. CALONGE: «El pontifex maximus y el problema de la distinción entre magistraturas y sacerdocios», A.H.D.E., XXXVIII, 1968, pág. 16). 


\section{BETICA.}

- (Iliberris, 2081) $=$ Duumvir + Pontifex perp.

- $($ Acinipo, 1348$)=$ Pontificalis + Duumvir.

- (Cisimbrium, 2098) $=$ Duumvir + Pontifex perp.

- (Mellaria, 2343) $=$ Duumvir bis + Pontifex perp.

- (Ulia, Habis, 5) = Duumvir + Pontifex sacror.

- $($ Urso, 5441 $)=$ Duumvir + Pontifex perp.

- $($ Tucci, 1677) $=$ Duumvir bis + Pontifex.

- $($ Tucci, 1684) $=$ Duumvir + Pontifex.

- (Urgavo, 2115) $=$ Duumvir + Pontifex divi Aug.

- (Iliturgicola, 1649$)=$ Duumvir + Pontifex.

\section{TARRACONENSE.}

- $($ Mancha Real, 3350$)=$ Duumvir + Pontifex Cáes. primus.

De la misma forma el esquema EDIL + DUUMVIR + PONTIFEX, por similares razones a las apuntadas ya, viene a corresponder en la Bética (donde se dan casi todos los casos) al esquema núméro 3, que predomina fundamentalmente en la Tarraconense.

Núm. 11. EDIL + DUUMVIR + PONTIFEX.

TARRACONENSE.

- (Saguntum, 3858) $=$ Edil + Duumvir + Pontifex.

BETICA.

- $($ Azuaga, $5547=2342)=$ Edil + Duumvir + Pontifex Aug.

- (Tucci, Cabezón, ET, 4) = Edil + Duumvir + Pontifex.

$-($ Isturgi, 2121) $=$ Edil + Duumvir + Pontifex.

- (Hispalis, 1188) $=$ Edil + Duumvir + Pontifex Aug.

Los casos en que se ha accedido desde la edilidad directamente al pontificado son contados, y corresponden todos a la Tarraconense. Seguramente tales pontificados debieron atender a los sacra de 
las ciudades, revistiéndolos individuos con limitadas posibilidades de avanzar en el cursus honorum local, no llegando a ocupar ni el duunvirato, ni el flaminado. En dos de los ejemplos siguientes es probable que se alterara el orden de los cargos, pues no es común iniciar la trayectoria pública con funciones religiosas.

Núm. 12. EDIL + PONTIFEX.

\section{TARRACONENSE.}

- (Murcia, 5945) $=$ Pontifex + Edil.

- (Saguntum, 3853) $=$ Edil + Pontifex.

- (Saguntum, 3854) $=$ Pontifex + Edil.

$-($ Saguntum, 3857$)=$ Edil + Pontifex.

Finalmente, tenemos algunas secuencias honoríficas muy particulares que, aunque excepcionales, confirman la pluralidad de opciones que ya señalábamos. Dado que son muy contadas las constataciones epigráficas al respecto, resulta difícil extraer conclusiones para cada uno de tales esquemas, cuya variedad, no obstante, indica la ausencia de un cursus honorum local regulado en sus diferentes etapas oficialmente, a diferencia de lo que parecen señalar los reglamentos municipales. Estos dan la impresión de no haber encontrado siempre una estricta aplicación práctica en ciertos aspectos, cuya interpretación real quizás distó de las estipulaciones legales.

Nü. 13. EDIL + DUUMVIR + PONTIFEX + AUGUR.

- (Azuaga, 5547).

Nü. 14. PRAEFECTUS + QUATTUORVIR + PONTIFEX.

- $($ Carmo, 5120 $)=$ Praef. C. Caes. + Quatt. potest. + Pontifex sacror. public.

Nim. 15. DECURIO + PONTIFEX + AEDILICIIS HONORIBUS FUNCTUS.

- (Tarraco, 4272). 
Núm. 16. EDIL + DUUMVIR + PRAEFECTUS + PONTIFEX + + AUGUR.

- (Obulco, 2149 a).

Núm. 17. QUATTUORVIR + PONTIFEX + AUGUR.

- (Carmo, 1380).

Núm. 18. AUGUR + QUINQUENAL.

- (Carthagonova, 3426).

Núm. 19. TRIUMVIR + QUATTUORVIR + AUGUR.

- (Ilici, 5950).

Núm. 20. OMNIBUS HONORIBUS IN RE PUBLICA SUA FUNC. TUS + SACERDOS.

- $($ Tarraco, 6093) $=$ OHRSF + Sacerdos Rom. et Aug.

- (Tarraco, Eph. Ep., VIII, p. 488 s, n. 199) $=$ OHRSF + Sacerdos Rom. et Aug.

Observamos de nuevo cómo el augurado es ejercido por individuos con carreras honoríficas muy completas, que mencionan tal dignidad en un lugar culminante. Los esquemas números 13 y 16 no significan más que la complejidad de otros más sencillos, el primero añadiendo el augurado, y el segundo enriqueciéndose además con el desempeño de la prefectura excepcional en sustitución de los magistrados normales. En tres de los casos citados (núms. 14, 17 y 19) la titulación duunviral ha sido reemplazada por el quattuorvirato, en el que se depositan similares competencias ejecutivas, aunque las denominaciones cambien probablemente en función de reestructuraciones administrativas internas (19). Más problemático resulta identificar correctamente el cargo de triumvir citado en la lápida ilicitana (20).

(19) Sobre estos pormenores, A. Degrassi: "Quattuorviri in colonie romane e in municipi retti da duoviri», M.A.N. L., 2, F. 6, 1950, págs. 281-345.

(20) Aparece enunciado antes del quattuorvirato en un epígrafe de Ilici (5950) dedicado a Hércules. Hïbner arroja ciertas dudas sobre la exactitud de tal lectura, donde debería leerse quizá la mención II vir. Para tener tal certeza habría que vol- 
El esquema número 15 resulta bastante singular $\mathrm{y}$, hasta cierto punto, difícil de interpretar. No creemos que las funciones y honores estén desordenadamente expuestos, pues no es lo frecuente. Probablemente debamos desechar también un orden inverso de los cargos. Reconocerlo así supondría que dicho notable tarraconense inició su trayectoria pública asumiendo los honores edilicios, no la magistratura en sí. Tal circunstancia podría indicar que existían obstáculos de algún tipo para el ingreso efectivo en la curia, inconvenientes que se compensaban con tales honores. Pero dichas rémoras, fuesen de fortuna, ascendencia familiar o cualificación jurídica personal, resultan inimaginables en alguien que acabó siendo decurión y que, por lo mismo, podría perfectamente haber aspirado a ingresar en el consejo comunal tras revestir cualquier magistratura. Si se respetó una secuencia directa en la exposición epigráfica, parece conveniente pensar que este personaje ingresó en la curia por adlectio, posteriormente desempeñó como pontífice y luego, no pudiendo optar a ninguna magistratura, por tener quizás una edad avanzada, se le distinguió con los honores edilicios.

Caracteres de excepción se dan en el esquema número 18, que reúne en una misma persona dos funciones de alta consideración. Por una parte la quinquenalidad, que por lo común se alcanza sólo tras un completo cursus; por otra el augurado, sobre el que ya hemos hecho las observaciones pertinentes. Carreras honoríficas de este tipo probablement obedezcan a circunstancias personales muy especiales o a iniciativas singulares de la comunidad, pues este individuo aparece dirigiendo importantes trabajos públicos (21). Queda, por último, el esquema número 20 , dentro del cual se hace casi imposible ubicar con exactitud el sacerdocio imperial, pues se marca una clara distinción entre dicha dignidad sacra y el conjunto de

ver a examinar detenidamentc la pieza. Hubiese sido una posibilidad recurrir a los III viri aediles que encontramos en ciertas ciudades italianas (E. MANNI: Per la storia dei municipii fino alla Guerra Sociale. Roma, 1947, págs. 123 ss.), pero la edilidad ilicitana parece corresponder al quattuorvirato (que es aedilicia polestate), puesto que la magistratura duunviral se encuentra explícitamente citada en otras inscripciones de dicha localidad. Esta observación impide, por tanto. transformar tal triunvirato en duunvirato. Es probable que estemos ante un caso similar al octovirato de algunas ciudades itálicas, o sea, una forma de magistratura colegiada, propia de comunidades en donde la vida municipal aún no había recibido su definitivo desarrollo romanizador, hallándose en una fase de transición desde los moldes indigenas (cfr. A. N. Sherivin-White: The Roman Citizenship, Oxford, 1973, págs. 72 s.). Recordemos que, similarmente, aparecen decenviri en Cartima (1953), y un $X$ v(ir) maximus se cita en Ostippo (5048).

(21) CIL. II, 3426: ... murum a porta Popillia ad turrim proximam ped(um) CXLVI et ultra turr(im) p(edum) XI d(ecreto) d(ecurionum) f(aciundum) c(uravit) i(dem)q(ue) p(robavit). 
competencias y honores civiles que se engloban en la expresión $O$. H.R.S.F., aunque probablemente se ejerció la función religiosa hacia el final del cursus.

\section{LOS HONORES RELIGIOSOS DISPENSADOS A PERPETUIDAD}

Pasemos, finalmente, a un aspecto peculiar del flaminado y pontificado municipales, su revestimiento a perpetuidad, cuestión que ha suscitado numerosos problemas. Cuando la denominación de un cargo sacerdotal va seguida de la mención perpetuus, ¿qué añade al título religioso dicho calificativo? Sabemos que las funciones del flamen duraban una anualidad, al término de la cual sólo en contados casos se efectuaba la renovación (22), y si ésta no tenía lugar el individuo volvía a la vida privada. Esto, a primera vista, podría parecer en abierta contradicción con el hecho de que algunos flamines aparezcan como perpetui en las inscripciones, y se han formulado algunas opiniones para explicarlo (23). Según MOMMSEN, anualmente el ordo designaba un flamen Augusti, que, una vez cumplido el periodo de su función, pasaba a formar parte de la categoría de flaminales, con el título de flamen perpetuus. En todo caso, los que no portan tal denominación lo hacen por negligencia, puesto que nadie entraba en la vida privada sin recibirla. Por su parte, HIRSCH FELD pensaba que los flamines perpetui eran aquellos que, tras su período de sacerdocio, seguían detentando los títulos y prerrogativas inherentes al cargo. Los demás conservarian tan sólo de

(22) La condición de flamen tendió a constituirse en el escalafón más alto del cursus honorum en numerosas ciudades, en la meta suprema de muchos notables municipales (J. GaGÉ: Les classes sociales dans l'Empire Romain, París, 1971, pág. 173). Al igual que las flaminicas, tales sacerdocios eran nombrados por decreto decurional. Así, tenemos en Complutum (3033) un flamen Romae et Aug(ustorum) d(ecreto) d(ecurionum) (cfr. CIL, II, 5488). Un caso particular, aunque procedente de una lápida africana (CIL, VIII, 7119, Cirta), muestra a un flamen perpetuus nombrado por sufragio popular, lo cual hay que considerarlo como una aclamación meramente formal, en una época de plena decadencia en los comicios populares. Tal condición de perpetuus, recibida ocasionalmente como sumo honor, una vez finalizada la anualidad en el cargo, era decidida también por decreto de la curia (Tanfanr: Op. cit., pág. 55). Curiosamente, sin embargo, ninguno de los flamines hispanos que fueron reelegidos para el cargo obtuvieron ulteriormente la condición de perpetuus. La referencia flamen bis la hallamos en Salacia. 34; Liria, 3792, 6014; Saguntum, 3864, 3865. Y en una ocasión (Villajoyosa. 3571) conocemos a un personaje que, además de ser duunviro en tres ocasiones, aparece citado como flamen IIII. En prácticamente todos estos ejemplos encontramos a personajes que recorrieron completas carreras honoríficas locales.

(23) Recogidas en EtIENNE: Op. cit., pág. 236, y Tanfani: Op. cit.. pág. 155. n. 36. Eventualmente la expresión perpetuus puede reemplazarse por otras similares: un flamen Iuliae Augustae in perpetum (Olisipo, 194). 
modo honorífico la mención de flaminalis, como el que aparece citado en una lápida del conventus Hispalensis (983), un tal C. Varinius Fidus, que había sido flamen de la Bética (24). Para MarquardT el origen del flaminado perpetuo habría sido análogo al del sevirato augustal perpetuo. El flamen Augusti, una vez cumplido su año de servicio, era investido con el derecho a conservar las prerrogativas honoríficas y la inmunidad correspondiente a su cargo, a lo que alude la fórmula honor flamonii perpetui ab ordine confertur. Finalmente, tenemos la opinión de ÉTIENNE (25), según la cual es raro que los flamines hayan olvidado hacer constar en los epígrafes su carácter de perpetuus, dada la gloria que tal título confería. Como el número de flamines distinguidos con la perpetuidad es más bien corto, todo parece dar a entender que tal reconocimiento era dispensado por el ordo con muchas restricciones, decidiendo sobre los méritos del sacerdote saliente, a quien podía renovársele la anualidad, algo poco frecuente, o concedérsele los honores a perpetuidad, algo más corriente, aunque muchos de ellos volvían inmediatamente a su condición particular. El ordo gozaba de amplias facultades para decidir al respecto (26). Que la anualidad en el cargo era cierta, aunque se recibiera el título de perpetuus, lo demuestra el que muchos de quienes lo disfrutaron pudieron acceder posteriormente a otras funciones, tanto políticas como religiosas (27).

Sin embargo, es factible observar cómo el flaminado perpetuo no se integra en las carreras honoríficas más densas y prolongadas, las que corresponden a los individuos con una amplia trayectoria de servicios y honores públicos. No puede dudarse de la alta dignidad social que confería dicha condición, puesta de relieve por

(24) ETIFnne: Op. cit., pág. 237.

(25) Ibidem.

(26) Cfr. CIL, XIII, 1751 = I. L.S., 4131 (Lugdunum): ... Sacerdote Q. Sammio... cui sanctissimus ordo Lugudunens(ium) perpetuitatem sacerdoti decrevit...; CIL, VIII, 4196 (Verecunda): L. Propertius... ob honorem flamon(ii) perpetui ab ordine in se conlat $(\mathrm{um})$... Ocasionalmente, el primero en ejercer un sacerdocio en su ciudad recibió posteriormente la perpetuidad de los honores, de ahí la fórmula primus et perpetuus, que encontramos en Caesarobriga (895) para una flaminica, en Suel (1944) para un seviro augustal, y en Cartima (1956) para una sacerdos. El seviro de Suel indica incluso que la distinción le ha sido conferida d(ecreto) d(ecurionum). Para el caso del flamen provincial, también la Tabla de Narbona nos pone en conocimiento de que el saliente del cargo podía conservar sus prerrogativas, e incluso su suplente (lín. 20) si había cubierto un mínimo tiempo de permanencia. Cfr. también: [po]ntif(ex) Caesalr [is] primus (Alcalá, 3350).

(27). Cfr. CIL, II, 5523, donde un duunviro continúó su trayectoria honorífica siendo sucesivamente flamen perpetuo y pontífice. 
DunCan-Jones (28) para el caso de Africa, donde con frecuencia es el sacerdocio más citado entre los personajes de rango ecuestre, aunque con sólidas raíces municipales. Pero también dicho autor resalta cómo ciertos equites podían alcanzar frecuentemente tal grado sin haber desempeñado antes cargos locales, es decir, en virtud del prestigio personal y familiar. Esta circunstancia concuerda con la ya señalada, y situaría al flaminado perpetuo como una opción honorífica, al estilo de los honores edilicios y decurionales, que compensaría la incapacidad de determinados individuos para escalar los más altos niveles del cursus honorum. Es de suponer que tales honores se recibirían a cambio de una aportación pecuniaria, bajo la forma de una summa honoraria (29), que revertiría en favor de la caja religiosa, siendo obligatoria, y a la que podrían añadirse otras cantidades aportadas voluntariamente pro honore, quizás tras una previa taxatio, como vemos en ciertos epígrafes africanos (30). A estas condiciones estarían dispuestos no todos los que cumplían su período de flaminado, sino sólo algunos, aunque a veces se den casos de individuos especialmente ansiosos de acumular honores,

(28) R. P. Duncan-Jones: «Equestrian rank in the cities to the African provinces under the Principate: an epigraphic survey», P.B.S. R., 35, 1967, pág. 156.

(29) Summa legitima que se repetiria ahora sólo por parte de quienes, habiendo sido previamente flamines efectivos, tuvieron ya la obligación de entregarla al revestir dicha función.

(30) Cfr. A. Beschaouch: "Taxatio et élections municipales en Afrique romaine», R.H.D., 45, 1967, págs. 483-488. Las pollicitationes hechas en favor del populus con motivo de una elección imponían una obligatoriedad moral respecto a su cumplimiento. Esto podía decantar las preferencias ciudadanas en favor de determinados munícipes, y quizá estos mecanismos jugaran importante papel. en circunstancias como las reflejadas en la ya citada inscripción de Cirta (CIL, VIII, 7119). Recordemos que la cuestión de las promesas públicas es un problema al que se alude ya en el estatuto de Urso (cap. CXXXIV), cuando todavía los comicios municipales tenían plena vigencia para decidir sobre los candidatos. La epigrafía hispana no se muestra generosa en datos sobre estos particulares, pero quizá un eco de tal obligatoriedad encontramos en una lápida de Corduba (2195), donde dos hermanos, Cornelii Restitutus et Africanus, cumplieron exacto flamonio un voto hecho por si llevaban a feliz término su gestión. Por otra parte, las summae honorariae significaron probablemente un refuerzo estimable para las, a menudo, exhaustas arcas municipales, y sabemos que bien por este $u$ otro conducto las curiae buscaron acrecentar el erario, incluso tomando iniciativas de dudosa legalidad, como el ofrecimiento del decurionado a individuos sin la edad reglamentaria, o la dispensa de los honores edilicios a personas cuya condición de libertos les impedía ocupar las magistraturas. En la misma línea el flaminado perpetuo suponia simplemente seguir disfrutando de las prerrogativas externas del cargo, no un ejercicio efectivo y prolongado, y tales honores, en muchos aspectos (lugar reservado en los espectáculos públicos, atributos visibles, estatuas, etc.), no debían diferir mucho de los detentados por quien asumía, con idéntica intención (prestigio social) los honores edilicios o decurionales. Todas estas opciones honoríficas podian, por tanto, ser of recidas por la curia a todo ex-magistrado o ex-sacerdote que estuviera dispuesto a pagar la correspondiente summa honoraria, aumentándola incluso con otras liberalidades particulares. 
como uno de Aquae Flaviae $(5617=2479)$, que revistió a perpetuidad tanto el flaminado como el pontificado (31).

$¿$ Podemos aplicar las observaciones anteriores al pontificado perpetuo? Nada impide hacerlo así, desde el momento en que la intención que movía tales concesiones honoríficas era similar. El pontificado, al igual que el flaminado, no era vitalicio, sino temporal, y debía durar probablemente una anualidad (32). No todos los flamines y pontífices alcanzaban el honor de perpetuus, lo que demuestra que solamente algunos, una vez finalizado su mandato, o quizás sin haber llegado a estrenar el cargo (33), conservaban en el futuro las prerrogativas y distinciones inherentes a aquél. Además, la perpetuidad afectaba no solamente al pontificado dedicado al culto imperial, sino al que tenía como competencias los sacra de la ciudad (34).

(31) Cfr. CIL, II, 1572, una sacerdos perpetua que lo fue en Ucubi, Jpsca e Iliberris.

(32) La Lex Urs., cap. LXVII, señala los casos en que debía realizarse una nueva elección de pontífices y augures: in conlegium pontific(um) augurumq(ue) in demortui damnative loco $h(a c)$ l(ege) lectus cooptatusve erit... Es decir, el puesto se perdía por muerte o condena del titular. Pero no hay que entender que tales circunstancias afectaran a alguien que ocupaba sin interrupción el cargo, sino a quien sufría cualquiera de ambos avatares durante la anualidad de su mandato. De no haber sido anual el pontificado sería difícil entender cómo algunos pontífices desempeñaron luego el flaminado (CIL, II, 1534; e incluso siendo pontif. perp., 1475), tuvieron la condición de salio (Saguntum, 3859), y, lo que resulta más problemático, revistieron ulteriormente el augurado (Obulco, 2132, 2149 a; Azuaga, 5547; Iliberris, 5513), sacerdocio que hubiera resultado incompatible en una misma persona con el pontificado vitalicio, pues ambos pertenecían a diferentes colegios y, además, el augur actuaba con total independencia en sus decisiones de cualquier poder superior, incluso religioso. Queda descartada la posibilidad de que tales pontífices, no siendo temporales en el cargo, hubieran cesado a tenor de una de las circunstancias expuestas en Lex Urs. cap. LXVII (damnatio), pues la indignidad consiguiente les habría inhabilitado para la vida pública.

(33) Es factible que la mención pontifex perpetualis de una lápida de Mellaria, si no se trata de un error de redacción; responda a esta dualidad de opciones, en el sentido de que perpetualis sería aquel individuo que, no actuando como pontífice en efectivo, había sido reconocido con los distintivos y honores de dicho sacerdocio y, tras haber sido nombrado como tal, aguardaba para poder disfrutarlos en la práctica. De la misma forma, la mención pontificalis (Acinipo, 1348-1349) debe indicar que el individuo había sido elegido para el cargo, pero estaba a la espera de tomar posesión oficialmente (la expresión equivaldría, por tanto, al designatus que acompaña en ciertos casos al título de duunviro con la misma intención). Lo corriente, no obstante, es que el pontificado lo recibiese como perpetuus quien antes lo había ejercido con efectividad, asumiendo el honor a cambio de ciertas summae o liberalidades. No es una casualidad que varios de los pontífices perpetuos se citen adoptando iniciativas munificentes. El de Mellaria (2343) costeó una conducción de aguas, y uno de lliberris (2086) es objeto del reconocimiento público precisamente ob merita. (expresión que frecuentemente se aplica al patronazgo: cfr. HaRMAND: Op. cit., pág. 346).

(34) Cfr. H. A. E., 6-7, 1023 (Ulia): Pont(ifex) sacrorum per(petuus). También CIL, II, 5120 (Carmo): [pontifex] sacrorum publicorum municipalium. 


\section{CONCLUSIONES}

Hasta que no dispongamos de una mayor documentación epigráfica será imposible confirmar o revisar algunas de las impresiones que hemos avanzado en el presente trabajo. No obstante, se pone de relieve cómo resulta problemático analizar la vida administrativa municipal con cánones excesivamente rígidos. Ya hemos visto que la realidad legal reflejada en algunos estatutos locales conservados no se confirma por una práctica, testimoniada epigráficamente, que nos muestra una gran variedad de situaciones personales y comunitarias patentes a través de las carreras honoríficas. Estas siguen unos esquemas, dentro de los cuales podemos distinguir aquellos que, por su reiteración, presentan las secuencias honoríficas más corrientes, y aquellos otros que por su complejidad y escasez de ejemplos parecen apuntar a circunstancias excepcionales que se nos escapan.

Resulta difícil, por otra parte, apreciar en su completo significado a qué responde la amplia gama de titulaciones en los cargos religiosos. Puede apreciarse una división general entre los que corresponden al culto imperial y los que conciernen a los sacra de la comunidad. Pero, aún así, la ubicación del flaminado o del pontificado en el cursus honorum local, su mayor o menor densidad según las distintas Provincias hispanas, e incluso los cambios en sus competencias que han podido darse, solamente podrían aclararse con un incremento de la epigrafía jurídica, lo cual es hipotético. No obstante, en estos problemas de titulación quizás se esconda no una cuestión de fondo, relativa a las actividades peculiares para las que comenzaron a funcionar en las ciudades hispanas tales sacerdocios de corte romano. Es factible que nos hallemos ante una mera complicación formalista, producto de una variedad estatutaria concerniente tanto al contenido particular como a la fecha en que comenzaron a regir todos y cada uno de los reglamentos municipales. Es decir, estariamos en cierto modo ante una cuestión similar a la que afecta a las magistraturas de las ciudades, donde unas veces encontramos duunviros y ediles, y otras se nos atestiguan quattuorviros simplemente, o quattuorviros aedilicia potestate. DEGRASSI (35) ya puso de relieve cómo por lo general existe en este apartado una gama de posibilidades, aunque las opciones se repartan

(35) Op. cit., en nota 19. 
según la categoría colonial o municipal de la población, pero existiendo casos en los que vemos a los magistrados de una misma ciudad cambiar de una a otra denominación, probablemente en virtud de ciertas alteraciones en los estatutos comunitarios.

Por otra parte, la misma situación de las funciones religiosas en el conjunto de las secuencias honoríficas corrobora el enorme peso de la vida religiosa oficial en la sociedad romana, y en concreto en las sociedades municipales hispanas (al menos los sectores privilegiados), donde los notables ambicionaron siempre las dignidades sacras como culminación o consolidación de sus trayectorias públicas. En este sentido, tanto el pontificado como el flaminado constituyeron objetivos supremos para quienes tenían sólo oportunidades a nivel político local. Frente a las ya tópicas aspiraciones de estos munícipes encumbrados por el prestigio familiar y la fortuna, y seducidos por el esplendor ecuestre o senatorial, la realidad demuestra que, al menos en Hispania, ese paso hacia las dignidades superiores del Estado fue dado por muy pocos, y quienes asi lo hacen no se identifican por lo común con los ciudadanos que a escala local ejercieron como pontífices y flamines. 


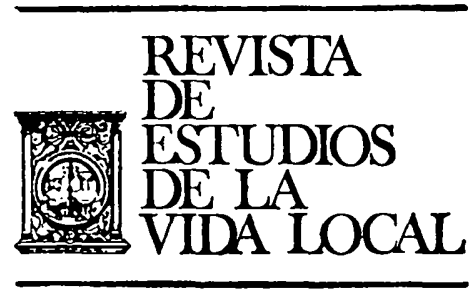

II. CRONICAS 
REVL-1981, núm. 209. RODRIGUEZ NEILA, JUAN-FRANCISCO. MAGISTRATURAS MUNICIPALES ... REVL-1981, núm. 209. RODRIGUEZ NEILA, JUAN-FRANCISCO. MAGISTRATURAS MUNICIPALES ... 